\title{
Development of an Empirically-based Conditional Learning Progression for Climate Change
}

\author{
Wayne Breslyn ${ }^{1 *}$, Andrea Drewes ${ }^{2}$, J Randy McGinnis ${ }^{1}$, Emily Hestness' ${ }^{1}$, Chrystalla Mouza ${ }^{2}$ \\ ${ }^{1}$ School of Education, University of Maryland, College Park, 2226 Benjamin Building, College Park, MD, USA, ²University of Delaware, School of \\ Education, 113 Willard Hall Education Building, Newark, DE, USA
}

*Corresponding Author: wbreslyn@umd.edu

\section{ABSTRACT}

Climate change encompasses a broad and complex set of concepts that is often challenging for students and educators. Using a learning progressions (LPs) knowledge system, we developed a LP that described student learning of climate change. In this exploratory study, we present findings from written assessments of climate change $(n=294)$ and in-depth interviews $(n=27)$ with middle school students. We examined learners understanding of four dimensions of climate change: The role of human activity, mechanism, impacts, and adaptation and mitigation. Findings were synthesized into a first step empirically supported LP for climate change that described a path from an initial to a sophisticated understanding of climate change.

KEY WORDS: climate change; education; learning progressions; environmental education

\section{INTRODUCTION}

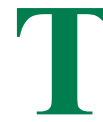

There is clear consensus among climate scientists that the earth is experiencing human-caused global warming (Cook et al., 2016). With wide ranging effects such as sea level rise, drought, severe weather, and impacts on the health of humans and ecosystems, climate change is a globally serious and disruptive phenomenon (IPCC, 2014; Melillo et al., 2014). Because of its breadth and complexity, it presents challenges to learners as well as science educators and researchers (Brickhouse et al., 2017; Sullivan et al., 2014; Wise, 2010).

Research on the difficulties associated with learning about climate change, global warming, or the greenhouse effect (GHF) initially focused on the identification of learners' misconceptions related to the topic. Boys and Stanisstreet led much of the early work on assessing students' understanding of the GHF (1993; 1997; 2001). While working alongside global colleagues, they also documented numerous common misconceptions around the world in various ages of students (Boys et al., 2009; Boys et al., 2008; Kilinc et al., 2008). Yet much of this work emphasized the identification of students' misconceptions outside of the context of instruction.

As the science education research community turned to exploring learning through conceptual change, there was a similar trend to apply a conceptual change theoretical lens to climate change education. Researchers sought to develop instructional models to minimize students' misconceptions, to increase the links between relevant science concepts, and to develop explanatory frameworks of climate change that were more scientifically accurate through techniques such as concept mapping and argument driven inquiry (Golden, 2011; Rebich and Gautier, 2005). These efforts in teaching for conceptual change involved carefully designed curricula that consider both climate change content and the frequent misconceptions or alternative conceptions held by learners.

However, conceptual change approaches often emphasized the scientific mechanisms at the expense of other societal or personal considerations that influence the educational context for learning about this scientifically, socially, and politically complicated phenomenon (Kirk et al., 2014). Klosterman and Sadler (2010) showcased the efficacy of using socioscientific issues as a context for learning about the mechanistic phenomenon of climate change, as well as its surrounding societal implications. Numerous successful strategies for teaching climate change include pedagogies that focus on the solutions, use local contexts to explore the phenomenon, and embrace the perceived sensitivity of the topic to build students' scientific literacy skills (Kirk et al., 2014). The next step is to prepare teachers to teach climate change in ways that link science and society and to appreciate the importance of integrating perceived sensitive topics by some such as climate change into their curriculum (Evagorou et al., 2014).

Climate change is a complex topic that is currently impacting the earth and will continue to do so in the future (IPCC, 2014). Encouraging the development of students' content knowledge and scientific literacy is critically important now to prepare them for their roles as citizens and future decision makers on how to address this global phenomenon (Boon, 2010; Sharma, 2012). The challenging nature of student learning about climate change has been clearly established in the research literature 
(Bodzin et al., 2014; Koulaidis and Christidou, 1999; Punter et al., 2011). These limitations are also readily observed in pre-service and in-service teachers' content knowledge (Boon, 2010; Liu et al., 2015; Hestness et al., 2011; McGinnis et al., 2011; Monroe et al., 2013), their lack of training and preparation on this topic (Hestness et al., 2014; Ratinen et al., 2013), and the need for teachers to experience exemplar pedagogy that is appropriate for climate change education (Evagorou et al., 2014; Feierabend and Eilks, 2010; Shea et al., 2016). There is a strong need for the science education research community to take a more prominent position toward preparing and guiding teachers on what are effective, meaningful, and appropriate climate change teaching approaches (McGinnis et al., 2016; Sharma, 2012).

The aim of this study is to offer this type of guidance to educators, researchers, and curriculum and assessment developers through the development of a climate change learning progression (LP) that is empirically grounded in how student learning develops as a result of instruction. We sought to create a LP that incorporated the findings from years of conceptual change research on climate change, yet was still flexible enough to be employed in various curricular efforts to build learners' scientific literacy on climate change.

\section{Theoretical Framework}

LPs provide a knowledge system framework for researching and describing how student understanding develops. LPs are descriptions of the increasingly sophisticated ways that learners think about a science topic as they become more acquainted with the science associated with the topic (Lehrer and Schauble, 2012). LPs are well suited for a complex and conceptually challenging topic like climate change.

LPs have been developed across numerous science topics, from physical forces and celestial motion (Alonzo and Steedle, 2009; Plummer and Kracjik, 2010) to biodiversity and ecological topics (Songer et al., 2009). These LPs can help teachers to grasp where their students will likely begin in their conceptual development which can inform their planning decisions (Alonzo and Steedle, 2009) and to develop formative modifications based on the students' actual learning trajectories (Furtak, 2012). LPs can act as a tool to describe curricular goals on content knowledge and skills, explore assessment techniques, and guide teaching practice. In summary, the use of LPs in research and during instruction can help identify and document the progressive development of student scientific thinking before, during, and as a result of instruction.

The steps to develop and revise LPs incorporate an iterative process of expert review and collection of student data to support the varying LP levels (Alonzo and Steedle, 2009; Shea and Duncan, 2013). An LP typically consists of levels describing increasingly sophisticated understanding (Duncan and Hmelo-Silver, 2009). We can broadly conceptualize an LP for climate change in three main segments, or levels: (1) An initial, limited understanding, (2) a developing understanding, and finally, (3) an advanced understanding as defined by consensus documents such as the Atlas of Science Literacy (AAAS, 2001) and the Next Generation Science Standards (NGSS Lead States, 2013).

\section{LP Development Approach}

We focus on the development of a LP which is supported by empirical data but still open to further investigation in different contexts such as student age and background (Hestness et al., 2016; McGinnis et al., 2017). This conditional climate change LP provides a solid foundation for continued research as well as providing urgently needed guidance to the education community on climate change education (for curriculum, instruction, and assessment).

We followed a development process for the conditional climate change LP detailed in our earlier reported study on the development of a conditional LP for sea level rise (Breslyn et al., 2016). This involves drafting a hypothetical LP based on the science education research literature, consensus documents such as the NGSS Lead States (2013) and the AAAS (2001), as well as communication with climate scientists on the topic. Data are then collected from learners, which are used to modify the hypothetical LP based on how well it describes actual student learning. Through several iterations the LP moves to a provisional status, and is termed a conditional LP.

The initial understanding, or Level 1, describes the ideas and knowledge a learner has before instruction or learning activities focused on climate change. Students tend to be at or near this level of the LP. At the opposite end of progression is the upper anchor, Level 4. At Level 4, learners hold a sophisticated scientific understanding of the causes and impact of climate change. While this level does not represent an end to learning all that there is known about climate change, it describes a level of understanding that reasonably could be reached upon completion of secondary school.

From a research perspective, the challenging part of developing an empirically supported LP is in identifying the middle levels of an LP (Gotwals and Songer, 2010). The initial level, or lower anchor, that learners bring to school in first grade and the most sophisticated level, or upper anchor, with which learners are expected to leave upon completion of secondary school are more readily determined and agreed upon. During the developing understanding segment of the LP, engagement with carefully selected and implemented instruction takes place and targeted learning occurs. More than just the addition of knowledge, learners often must modify or replace their existing ideas with more generative and sophisticated ones.

A useful analogy for the middle levels of an LP is that of transition states in chemical reactions. Much like with reactants and products in a chemical reaction, we are able to study and measure student understanding before and after learning. However, when learning is taking place, it is a more dynamic and hidden process, similar to chemical transition states. In both cases, different contexts can result in varying paths 
being followed. In developing an LP, a challenge is to collect data that allows for an accurate description of the changes to student understanding as learning is taking place, while also being aware that not all students may follow the same path toward climate literacy.

To develop a robust LP, data from a variety of sources must be collected and analyzed. This is necessary given that instruction can influence how student understanding develops. In this article, we present findings from our research with middle school students as well as our analysis of the research literature and provide a comprehensive inventory of individuals' ideas about climate change and an LP of how climate change understanding develops.

The culmination of our research in climate change education is a proposed, empirically supported LP for climate change presented in Table 1 in the discussion section. Our LP is framed by consideration of four primary constructs: Human activity, mechanism, impacts, and mitigation, and adaptation. Based on consensus documents, the research literature, and data collected in our investigation, as well as review by practicing climate scientists, the climate change LP represents a robust and empirically supported description of how climate change understanding develops.

\section{Study Aim}

Using a LPs knowledge system framework, in this exploratory study, we report our efforts to identify, describe, and organize the development of learners' understanding of climate change in an empirically supported LP. The LP framework is a wellsuited analytical tool for investigating how student thinking develops over time (Duschl et al., 2007).

Our primary research question is "How do learners progress over time from an initial to a more sophisticated understanding of climate change?"

Secondary research questions include:

- What common alternative or misconceptions do learners have about climate change?

- What are the qualitative shifts that take place as understanding advances as a result of instruction?

\section{METHODS}

The study employed a mixed methodology with quantitative and qualitative data from students in two Mid-Atlantic States in the United States. Data were collected from $6^{\text {th }}$ and $8^{\text {th }}$ grade middle school students (approximately ages 11-14) by two research teams using the same instruments and protocols. Schools provided a demographically diverse sample as reported in Table 2.

All sites used the same curriculum; however, teachers' implementations of the curriculum varied based on state and district curricular priorities, the regional climate change context, and teachers' own pedagogical preferences and content knowledge. As the focus of our study is on developing a robust description of learning, and not on evaluating the curriculum or comparing $6^{\text {th }}$ and $8^{\text {th }}$ grade learners, differences in curricular implementation, and student grade level are seen to broaden the context of the study.

The selection of middle school students was based on their ability to productively access complex climate concepts (McBeth et al., 2011) as well as the inclusion of the topic of weather and climate in many middle school curricula. Within the context of the middle school environment, it is possible to measure understanding before instruction, observe learning taking place, and then, measure how thinking has changed. The resulting data are therefore substantial and varied, and can support the development of a robust description of learning. Our study design is presented in Figure 1.

In this study, data were collected before, during, and after instruction through a multiple-choice instrument, participant interviews, and classroom observations. The climate science knowledge assessment instrument (CSKAI) instrument, along with the interview protocol described below, is available in a previous publication (Hestness et al., 2016).

\section{Instrument Development}

\section{CSKAI}

Students' climate science knowledge was measured using an 18-item multiple-choice instrument developed over a 2-year time frame before this study. The instrument assessed student understanding of four primary climate change constructs: Human activity, mechanism, impacts, and mitigation and adaptation strategies. These constructs were chosen based on their inclusion in NGSS and AAAS Science Literacy Maps (AAAS, 2001), grounded in prior climate science education research literature, and informed by feedback from practicing educators. The CSKAI was administered to students before and after instruction.

The CSKAI exhibits an internal reliable and valid structure from a psychometric perspective (Drewes et al., 2017). It has a Cronbach's (1951) coefficient alpha of 0.803, a mean item discrimination of 0.52 and the instrument mean difficulty is $70.0 \%$. All of these indices should be interpreted as very good by statistical guidelines (Ebel, 1954; Kaplan and Sacuzzo, 1997; Thorndike, 1982).

\section{Participant interviews}

We used an open-ended interview protocol developed for the study with a purposively selected subset of students $(\mathrm{n}=27)$ who completed the CSKAI. Participants were selected to represent a range of knowledge of climate change as determined by results of the CSKAI. To probe content understanding, students were interviewed before and after instruction. These interviews sought to elicit student thinking on the four primary areas of climate change measured in the CSKAI.

All interviews were transcribed and coded independently by two researchers to identify emerging themes. A high degree of inter-rater agreement $(85 \%)$ was observed between coders. 
Table 1: A conditional LP for climate change

\section{Primary \\ Constructs}

Human

\section{Students are able to explain}

that human activity is contributing to a warming earth. Students may state that human activity is producing gases or air pollution but they do not relate this to $\mathrm{CO}_{2}$ or use of fossil fuels

Mechanism Students are able to relate the presence of certain gases in the atmosphere to a warming earth but do not specify specific gases or the mechanism

Impacts

Students are able to explain that a warmer climate will affect humans and ecosystems but do not elaborate on specific impacts. They may confuse scientific certainty and projections with opinion and generally hold no realistic timeframe for climate change

Mitigation Students are able to explain and that simple actions individuals adaptation can take, such as conserving energy, can help slow climate change but cannot describe why. They can describe an action individuals can take to adapt to climate change

\section{Level 2}

Students are able to explain that human use of fossil fuels for energy generates $\mathrm{CO}_{2}$ and it is the primary cause of climate change. Students can explain that ozone and the ozone hole are not major factors in climate change

Students are able to describe that greenhouse gases trap energy from the sun inside the earth's atmosphere causing the earth to warm and that $\mathrm{CO}_{2}$ is primarily responsible for the enhanced GHF Students acknowledge that excess $\mathrm{CO}_{2}$ does not escape into outer space

Students are able to identify local and global impacts of climate change and can provide specific examples. They state that scientists are relatively certain that climate change is happening now or will happen in the near future

Students are able to identify a limited number of actions individuals, communities, and countries can take to slow the rate of climate change or identify simple measures to adapt to the impacts of climate change
Level 3

Students are able to name
specific fossil fuels (e.g. coal,
oil, gas) and can distinguish
between non-fossil fuel energy
sources (nuclear, wind, solar).
Students can describe that
plants remove some of the
human generated $\mathrm{CO}_{2}$ from the
atmosphere and may mention
the basics of the carbon
cycle (such as photosynthesis
and respiration)

Students are able to describe how energy from the sun reaches the earth's surface and is converted to heat energy and that some of the heat energy is absorbed by $\mathrm{CO}_{2}$ and other GHGs that cannot escape into outer space and this energy is causing the earth to warm

Students are able to describe local and global impacts of climate change and can provide examples of how these will vary geographically. They can explain that scientists use evidence from multiple sources and that climate change is happening now and is projected to increase in severity over time Students are able to describe several scientifically valid mitigation and/or adaptation strategies to reduce the negative impacts of climate change. Students can also describe how these actions relate to the mechanism of climate change
Level 4

Students are able to describe the rate at which humans use fossil fuels for energy and the rate at which $\mathrm{CO}_{2}$ is recaptured by oceans and vegetation.

Students can describe the current imbalance between these two rates and the related impact on the carbon cycle.

Students are aware of other GHG's generated by human activities

Students are able to provide a mechanism for the enhanced GHE at the molecular level. Students also can connect the mechanism to human use of fossil fuels and the current imbalance in the carbon cycle and elevated $\mathrm{CO}_{2}$ concentrations. Students are also aware of positive feedback loops, such as albedo, that influence the mechanism

Students are able to describe local and global impacts of climate change. They can also explain that climate models are based on multiple sources of evidence and can list several sources. They understand that future impacts are based on scientific projections and may vary but the models are reliable and continue to improve with scientific research

Students are able to identify several scientifically valid mitigation and adaptation strategies at the national and international levels that can slow rate of climate change. Students can compare and contrast each strategy as well as its cost, effectiveness, and regional relevance

GHF: Greenhouse effect, $\mathrm{CO}_{2}$ : Carbon dioxide

Table 2: School location, characteristics, and demographics

\begin{tabular}{|c|c|c|c|}
\hline Location & School characteristics & Demographics & Sample size \\
\hline Site one $\left(6^{\text {th }}\right.$ grade $)$ & Suburban, technology-based charter school & $\begin{array}{l}65 \% \text { African American, } 5 \% \text { Asian, } 14 \% \text { Hispanic, } 10 \% \\
\text { Caucasian, } 5 \% \text { of two or more races }\end{array}$ & 42 \\
\hline Site two $\left(6^{\text {th }}\right.$ grade $)$ & Suburban, dual language charter school & $\begin{array}{l}14 \% \text { African American, } 2 \% \text { Asian, } 57 \% \text { Hispanic, } 26 \% \text { White, } \\
1 \% \text { of two or more races }\end{array}$ & 221 \\
\hline Site three $\left(8^{\text {th }}\right.$ grade $)$ & Suburban, public school & $\begin{array}{l}33 \% \text { African American, } 3 \% \text { Asian, } 7 \% \text { Hispanic, } 54 \% \text { White, } \\
3 \% \text { of two or more races }\end{array}$ & 31 \\
\hline
\end{tabular}

\section{Classroom observations}

Classroom observations were conducted during instruction as a way to provide additional data to support LP development, Observations included direct instruction, students working independently on online activities, and small group discussions.
Each student received approximately $5 \mathrm{~h}$ of instruction on climate change over 2 weeks. Teachers taught multiple classes resulting in a total of $32 \mathrm{~h}$ of observations of climate change teaching and learning collected across the three participating schools. Combined, these data sources offered sufficient and 


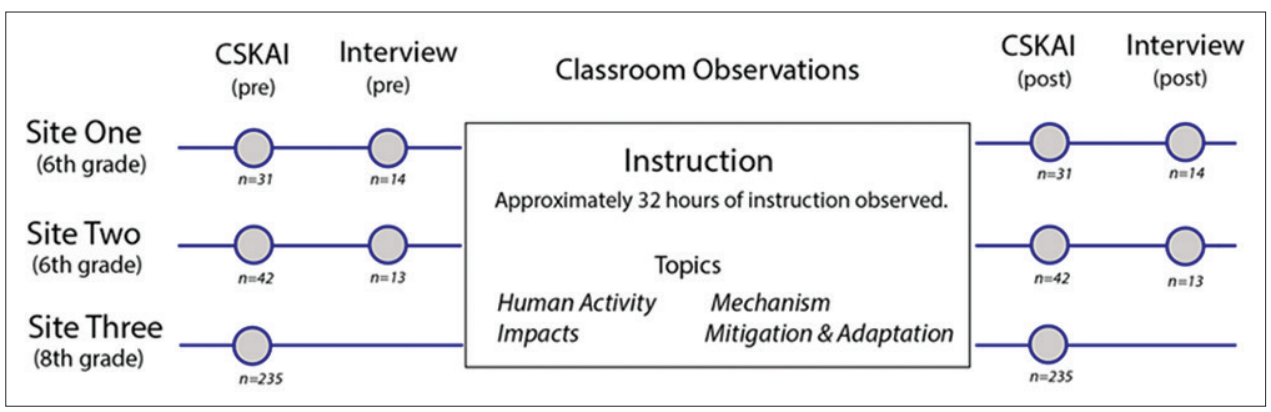

Figure 1: Design of study for development of a Climate Change Learning Progression. *CSKAl: Climate Science Knowledge Assessment Instrument

multiple opportunities to observe student learning and provide data for LP development.

As a final step to increase the content validity of the LP, expert climate scientists $(\mathrm{N}=3)$ provided feedback of our draft LP. This step resulted in a number of essential modifications to the upper levels of the LP.

\section{RESULTS}

Our research question was, "How do learners progress over time from an initial to a more sophisticated understanding of climate change?" We report our findings for each of the four constructs: Human activity, mechanism, impacts, and mitigation and adaptation.

The overall goals of the study were to develop a theoretical and empirically supported LP that described how learning about climate change progresses and to document the barriers and opportunities for learning. To accomplish this, we report what is known about student learning, alternative conceptions held by students, and statistical analysis of student learning for each construct. Findings from the research literature are included which contribute to the development of a robust and more widely generalizable LP.

\section{Findings for the Construct "Human Activity"}

The construct of human activity centers on student explanations of how human activity contributes to an increase in global temperatures and a changing climate. The role of fossil fuels and carbon dioxide $\left(\mathrm{CO}_{2}\right)$, as well as renewables and nuclear power, are also included in this construct. The imbalance between the amount of $\mathrm{CO}_{2}$ entering and being removed from the atmosphere represents an advanced understanding of these ideas.

Our data indicated that middle school students recognize the relationship between fossil fuels and global warming, although they may not understand the mechanism. Cars, and other forms of transportation, along with factories, are seen as the major contributors. Students often attribute climate change to a number of peripheral or unrelated human activities, listed in Table 3.

The analysis of our data detected many alternative conceptions similar to those reported in the literature:

- Pollution (interview $52 \%$ pre, $41 \%$ post; CSKAI pre $28 \%$, post $10 \%$ ) and littering (interview $22 \%$ pre, $15 \%$ post) cause climate change
- Nuclear power generation causes climate change:

- Using less nuclear power will reduce $\mathrm{CO}_{2}$ (CSKAI pre $22 \%$, post $22 \%$ )

- Nuclear generation produces $\mathrm{CO}_{2}$ (CSKAI pre 54\%, post $23 \%$ )

- Earth's temperatures are rising due to heat from nuclear power plants (CSKAI pre 19\%, post 2\%).

- Chlorofluorocarbons (CFCs) were not stated directly by students although deterioration of the ozone layer was a persistent concept (interview: $48 \%$ pre, $41 \%$ post)

- Artificial fertilizers were mentioned only once (interview data).

In addition to the alternative conceptions reported in the literature, we identified new ones in our data. Some students held the conception that rising temperatures were largely due to the heat generated from "hot exhaust from cars," "grills and stuff that lets off hot air," and even "breathing in general is just making the atmosphere warmer" (interview: Pre 18\%, post $7 \%$ ). Some students also viewed humans breathing as a significant source of $\mathrm{CO}_{2}$ (interview: $11 \%$ pre, $11 \%$ post). " $\mathrm{CO}_{2}$ can come from ... we breathe $\mathrm{CO}_{2}$ out, that's the first thing."

Based on items related to human activity in the assessment instrument, a paired t-test of pre-instruction $(\mathrm{M}=2.79$, standard deviation $[\mathrm{SD}]=1.47)$ and post-instruction responses $(\mathrm{M}=4.12$, $\mathrm{SD}=1.36$ ) found that student scores significantly improved after instruction $(\mathrm{t}(293)=15.787, \mathrm{p}<0.001)$. An effect size that accounted for the correlation between these scores was calculated (Dunlap et al., 1996). This Cohen's d effect size was 0.93 and should be interpreted as a large to very large effect (Cohen, 1988). There were six multiple-choice items related to the human activity construct and, on average, students improved by 1.32 items $(\mathrm{SD}=1.43$ ) or a $22 \%$ improvement.

\section{Findings for the "Construct Mechanism"}

The construct of mechanism represents the physical phenomena that drive climate change, with an emphasis on the enhanced $\mathrm{GHF}$ and the role of $\mathrm{CO}_{2}$. For some aspects of mechanism, students held ideas that were resistant to change, in particular $\mathrm{CO}_{2}$ being removed from the atmosphere by escaping into space and the role of ozone in climate change.

However, students also experienced the largest gains for this construct. Students gained in several concepts central to understanding the enhanced GHF: 
- Rising temperatures are due to changes in the amount of greenhouse gases in the atmosphere (CSKAI pre 34\%, post $81 \%$ )

- Heat from the sun is trapped and warms the earth (CSKAI pre $51 \%$, post $65 \%$; interview: Pre $36 \%$, post $64 \%$ )

- Heat trapped by greenhouse gases leads to more intense storms (CSKAI pre $27 \%$, post $55 \%$ ) (Table 4 ).

In addition to those reported in the literature, our study identified several more alternative conceptions previously unreported:

- $\mathrm{CO}_{2}$ is removed from the atmosphere by escaping into space (interview $33 \%$ pre, $44 \%$ post)

- Ozone layer depletion causes an increase in temperatures on earth (interview pre $48 \%$, post $41 \%$ )

o A hole in the ozone layer lets heat enter earth's atmosphere (CSKAI pre $23 \%$, post $6 \%$ )

o Banning chemicals that break down the ozone layer would reduce impacts of climate change (CSKAI pre $32 \%$, post $15 \%$ )

o Ozone layer depletion will lead to future intense storms (CSKAI pre $37 \%$, post $17 \%$ ).

- The sun is "releasing more energy" and causing the earth to warm (CSKAI pre $19 \%$, post $6 \%$ ).

The finding students believe $\mathrm{CO} 2$ escapes into the atmosphere appeared to us to result from these students misinterpreting textbook diagrams of the GHF. Diagrams frequently use arrows to show some of the infrared radiation emitted by the earth passing through the atmosphere into space. Some students in our interviews stated that this represented $\mathrm{CO}_{2}$ escaping into space. Unlike the interview, no diagram was present for the CSKAI question, "How is $\mathrm{CO}_{2}$ removed from the atmosphere?" Students (pre 66\%, post 76\%) selected "plants absorb $\mathrm{CO}_{2}$ for food" while fewer (pre $11 \%$, post $10 \%$ ) selected that " ${ }^{2} \mathrm{CO}_{2}$ escapes into space."
Our extensive set of classroom observations supports findings about students' ideas about ozone and global warming. Tellingly, after explicit instruction that warmer temperatures were not caused by a hole in the ozone layer, as well as interaction with a PhET simulation of the GHF, there was considerable disagreement among students about whether the statement "Chemicals creating a hole in the ozone layer are causing Earth's average global temperature to rise" was correct. Most students voted that the statement was accurate, indicating they still held an alternative conception about ozone and global warming.

Based on items related to the mechanism in the assessment instrument, a paired t-test of pre-instruction $(\mathrm{M}=1.61$, $\mathrm{SD}=1.14)$ and post-instruction responses $(\mathrm{M}=2.88, \mathrm{SD}=1.02)$ found that student scores significantly improved after instruction $(\mathrm{t}(293)=16.590, \mathrm{p}<0.001)$. The Cohen's d effect size was 1.17 and should be interpreted as a very large effect (Cohen, 1988). There were four multiple-choice items related to this construct, and on average, students improved by 1.27 items $(\mathrm{SD}=1.31)$ or a $32 \%$ improvement.

\section{Findings for the Construct "Impacts of Climate Change"}

This construct focuses on the impact a changing climate will have on humans, ecosystems, and the physical world. Sea level rise, drought, or extreme weather is examples of these impacts. This construct also includes how certain scientists are that climate change is taking place and the nature of future climate predictions.

Overall, students understood that climate change would affect humans and ecosystems and lead to rising sea levels. Our analysis of interview data indicated that students were able to identify a variety of impacts of climate change such as extreme weather effects, sea level rise, drought, and food insecurity. Our analysis of classroom observations revealed

\footnotetext{
Table 3: Common alternative conceptions about human activities and climate change

\begin{tabular}{ll}
\hline Alternative conception & Selected references \\
\hline The GHF is caused by pollution (in a general sense)* & $\begin{array}{l}\text { Punter et al. (2011), Gowda et al. (1997), Koulaidis and Christiadou (1999), Lee et al. (2007), } \\
\text { Shepardson et al. (2009) }\end{array}$ \\
The GHF is made worse by litter* & Boys and Stanisstreet (2001), Daniel et al. (2004), Gowda et al. (1997) \\
The GHF is made worse by nuclear power plants* & Boys and Stanisstreet (1993), Boys and Stanisstreet (2001) \\
The GHF is made worse by artificial fertilizers & Kilınç et al. (2008), Liarakou et al. (2011) \\
The GHF is made worse using CFCs* & Boon (2010), Hansen (2010), Kilınç et al. (2008) Punter et al. (2011)
\end{tabular}

*Items with an asterisk were also found in the current study. CFC: Chlorofluorocarbons, GHF: Greenhouse effect
}

Table 4: Common alternative conceptions about the mechanism of climate change

\begin{tabular}{ll}
\hline Alternative conception & Selected references \\
\hline $\begin{array}{l}\text { The GHF is caused or made worse by ozone layer depletion, or holes in the } \\
\text { ozone or atmosphere* }\end{array}$ & $\begin{array}{l}\text { Niebert and Gropengieber (2014), Hansen (2010), Reinfried et al. (2012), } \\
\text { Shepardson et al. (2009) } \\
\text { The GHF is caused by pollution (in a general sense)* }\end{array}$ \\
$\begin{array}{l}\text { In the GHF, gases form a layer that acts like the glass of a greenhouse } \\
\text { The GHF is made worse using CFCs* }\end{array}$ & Niebert and Gropengieber (2014), Shepardson et al. (2009) \\
The GHF is made worse by litter* & Boon (2010), Hansen (2010), Punter et al. (2011), Kilıç et al. (2008) \\
\hline
\end{tabular}

CFC: Chlorofluorocarbons, GHF: Greenhouse effect 
that some students believed global warming had affected them personally. For example, one student shared that during Hurricane Sandy (October 22-29, 2012 in the USA) family members in New York City experienced flooding and their pets drowned.

Of the four constructs, students held more sophisticated understandings about the impacts of climate change and had fewer alternative conceptions (listed in Table 5).

In our study, we detected additional student alternative conceptions previously unreported:

- $\mathrm{CO}_{2}$ is unhealthy/toxic (interview pre $4 \%$, post $19 \%$ )

- Oceans and lakes will dry up due to a warming earth (interview pre $7 \%$, post $11 \%$ )

- Projections are uncertain as they are based on scientists' opinions (CSKAI pre $20 \%$, post $18 \%$ )

- Projections predict the future with $100 \%$ accuracy (CSKAI pre $22 \%$, post $19 \%$ ).

A number of students also answered that climate change projections are "based on available data and predict future temperature with complete accuracy" (CSKAI pre 22\%, post $19 \%$ ). Students responding that "based on available data and may actually be lower or higher than estimated." rose modestly from $43 \%$ before instruction to $54 \%$ postinstruction.

Of particular note was students' understanding of certainty in scientific predictions. In response to the question "Climate change projections for the future are.," a consistent number of students (CSKAI pre $20 \%$, post $18 \%$ ) responded that climate change predictions are "relatively uncertain because they are based on scientists' opinions, which can be wrong." In explaining their CSKAI response, students responded:

"Opinions can be wrong. If an opinion is wrong you won't know until it happens. Unless there is proof of this how would anyone know what will happen in the future?"

"The theories about climate change vary around all scientists. Some are recognized as correct or incorrect but all are not fully backed up with the data that we have right now and most are opinions."

Based on items related to the effects of climate change in the CSKAI, a paired t-test of pre-instruction $(\mathrm{M}=2.37, \mathrm{SD}=1.07)$ and post-instruction responses $(\mathrm{M}=2.97, \mathrm{SD}=1.07)$ found that student scores significantly improved after instruction $(\mathrm{t}(293)=8.147, \mathrm{p}<0.001)$. The Cohen's $d$ effect size was 0.56 and should be interpreted as a medium effect (Cohen, 1988). There were four multiple choice items related to this construct and on average the students improved by only 0.6 items $(\mathrm{SD}=1.16)$ or a $15 \%$ improvement.

\section{Findings for the Construct "Mitigation/Adaptation"}

The previous three constructs, human activity, mechanisms, and impacts, support an understanding of what can be done to mitigate, or lessen the impacts of climate change, as well as strategies to adapt to a changing climate. Following instruction, students achieved only $66 \%$ accuracy on the mitigation/ adaptation construct, while mechanisms, human activity, and impacts were all higher $(72 \%, 69 \%$, and $74 \%$, respectively). In this sense, mitigation/adaptation can be viewed as a culminating construct that requires a thorough understanding of the three prior constructs and may be why student CSKAI scores were lowest for this construct.

In general, students' alternative conceptions about mitigation and adaptation were based on their thinking about human activities and the mechanism of climate change. Therefore, a table of alternative conceptions is not included for mitigation and adaptation.

Many students (interview pre $67 \%$, post $78 \%$; CSKAI pre $63 \%$, post $72 \%$ ) thought that driving less was an action that would slow or stop the earth from getting warmer. Using fewer fossil fuels is also present in interview data (pre 19\%, post $26 \%$ ), often related to the use of coal, and walking or biking rather than driving. Students suggested a number of actions that governments could take, including offering financial incentives, making more regulations, or better city planning. In addition, public education was mentioned in interviews (pre 19\%, post $11 \%$ ).

Of particular note were students' ideas about when climate change is taking place. In interviews, students were asked when they thought people will be affected by climate change. Student responses (pre $\mathrm{n}=18$, post $\mathrm{n}=21$ ) varied widely between Site 1 and Sites 2 and 3.

The pre- and post-instruction data shows that students at Site 1 shift toward perceiving the impacts of climate change as taking place sooner or already are happening. For Sites 2 and 3 the opposite shift occurred with students tending to see the impacts of climate change happening further in the future.

Students seeing the impacts of climate change taking place now explained their reasoning as:

"It's actually happening, some parts of it's happening now. Some of it is going to happen later... because it's getting warmer and people are getting warmer, I mean hot. Places are getting hotter. The ice is melting."

\section{Table 5: Common alternative conceptions about the impacts of climate change}

\begin{tabular}{ll}
\hline Alternative conception & Selected references \\
\hline Enhanced GHF will lead to more cases of cancer (e.g., skin cancer)* & Liarakou et al. (2011), Punter et al. (2011), Boys and Stanisstreet (2001) \\
Enhanced GHF will lead to more deaths from heart attacks & Punter et al. (2011), K1lınç et al. (2008), Boys and Stanisstreet (2001) \\
Enhanced GHF will lead to more earthquakes & Punter et al. (2011), K1lıç et al. (2008), Boys and Stanisstreet (2001) \\
Warmer global temperatures will cause sea levels to fall* & Boon (2010), Shepardson et al. (2009) \\
\hline
\end{tabular}


"I guess, from what I've heard on the radio, it's already happened. It's still happening."

Students who saw climate change as a future event varied in their reasoning and estimates.

"If people don't start doing something, then it could be in a couple years."

"It could start happening.... it probably will start happening in maybe a hundred or so years, but I don't think it'll happen as soon as a month because climate change is over a long period of time."

"In, like, three--four hundred years or something like that. The earth is a big place and it can't just happen."

Based on items related to mitigation and adaptation of climate change in the assessment instrument, a paired t-test of preinstruction ( $\mathrm{M}=1.75, \mathrm{SD}=1.08)$ and post-instruction responses $(\mathrm{M}=2.65, \mathrm{SD}=1.19)$ found that student scores significantly improved after instruction $(\mathrm{t}(293)=11.836, \mathrm{p}<0.001)$. The Cohen's d effect size was 0.79 and should be interpreted as a large effect (Cohen, 1988). There were four multiple choice items related to this construct and on average students improved by 0.9 items $(\mathrm{SD}=1.31)$ or a $22.5 \%$ improvement.

An Empirically-based Conditional LP for Climate Change As a result, of our comprehensive examination of the literature as well as our analysis of empirical data that we collected on student thinking regarding climate change, we were able to develop a first step, empirically supported conditional LP for climate change. Table 1 represents the synthesis of our findings, the research literature, and consensus documents in the form of an LP for climate change.

The conditional climate change LP is divided into four levels. Level 1, or the lower anchor, represents student thinking prior to instruction (Duschl et al., 2007). Level 4, the upper anchor, is the consensus view (Mohan et al., 2009) on what learners would know and understand. The middle levels, Level 2 and 3 , form the core of the LP and are often more challenging to measure and describe (Shea and Duncan, 2013).

To maintain conceptual coherence, the constructs presented in the conditional climate change LP were purposively sequenced to address the role of humans, followed by relevant mechanistic science concepts, the impacts of a changing climate, and culminating with mitigation and adaptation strategies.

\section{DISCUSSION}

Using multiple sources, including consensus documents, the science education research literature, and original data analyzed collected from middle school students in the USA, in this exploratory study, we were able to develop an empirically based conditional LP for climate change. The LP focuses on the role of human activity, mechanism, impacts, and mitigation and adaption to climate change.

Our study found support for many earlier reported findings concerning students' understanding of climate change constructs and alternative conceptions. A prominent example was students' conception of ozone as a major driver of climate change, which many students in our study maintained after a significant amount of instruction on climate change. The persistence of this alternative conception points to a critical need for specific instruction about the scientifically understood role of ozone in global warming.

Our study also identified several previously unreported findings. First, students often explained that $\mathrm{CO}_{2}$ was removed from the atmosphere by escaping into outer space. This explanation was more frequent when a diagram illustrating the GHF was present for them to view. Because this alternative conception could influence students' ideas about what actions can be taken to mitigate climate change, further research is needed, in particular on how diagrams of the GHF promote alternative conceptions about $\mathrm{CO}_{2}$ removal from the atmosphere.

The second finding deals with students' ideas about scientific certainty. Even after instruction, many students thought that scientists' projections about climate change are based on opinion ( $20 \%$ pre, $18 \%$ post) rather than on analysis of valid empirical data. A similar conception was found in a study on sea level rise projections (Breslyn et al., 2016). While instruction did not directly address scientific uncertainty, it was anticipated that exposure to data about climate change would result in students shifting away from this thinking. However, this was not the case and highlights once again the need for explicit instruction about scientific uncertainty and climate change projections.

Finally, students' conceptions of the timeframe over which climate change is taking, or will take place, varied widely between our three research sites. This highlights the critical need for a robust and empirically supported description of how student understanding of climate change develops over time. We posit that our conditional LP on climate change presented in Table 1 would likely have guided teachers at Sites 2 and 3 to address student ideas about current and predicted effects of climate change in a more thorough manner.

To conclude, it should be emphasized that learners should not be expected to attain a Level 4 understanding of climate change in a brief instructional time frame. In our study, which involved three times more climate change instructional time than average student in the USA receives in a year (Plutzer et al., 2016), most students progressed from a Level 1 to a Level 2, with only some students achieving a Level 3 understanding. None reached a Level 4. As they continue their education, the expectation is that these students will progress due to appropriate instruction in their understanding of climate change. The conditional climate change LP we have carefully developed offers an empirically supported conceptual framework that can be put to use now by curriculum, instruction, and assessment developers, as well as by educators (in formal and informal settings) who have a professional responsibility (McGinnis et al., 2016) to guide students toward understanding a scientifically informed view of climate change. 


\section{LIMITATIONS}

An LP for any topic should be considered tentative and open to change based on additional empirical data and analysis. The LP presented here is based on prior research, multiple data sources, and consensus documents of what a student should understand. However, we recognize that is possible, even probable, that in different contexts alternate paths to understanding may emerge. For example, age, background, and instruction could influence how climate change understanding develops. Further, in some geographic contexts climate change is a sensitive issue with students having been exposed to the topic at home and through media before instruction. Therefore, the first step nature of our conditional LP should be taken into account, and judicious care should be taken in its use.

\section{ACKNOWLEDGMENTS}

This material is based upon work supported by the National Science Foundation under Grants \#1043262 and 1239758. The opinions, findings, and conclusions or recommendations expressed in this study are those of the authors and do not necessarily reflect the views of the NSF.

\section{REFERENCES}

Alonzo, A.C., \& Steedle, J.T. (2009). Developing and assessing a force and motion learning progression. Science Education, 93(3), 389-421.

American Association for the Advancement of Science. (2001). Atlas of Science Literacy. Washington, DC: American Association for the Advancement of Science (AAAS) and the National Science Teachers Association.

Bodzin, A.M., Anastasio, D., Sahagian, D., Peffer, T., Dempsey, C., \& Steelman, R. (2014). Investigating climate change understandings of urban middle-level students. Journal of Geoscience Education, 62(3), 417-430.

Boon, H.J. (2010). Climate change? Who knows? A comparison of secondary students and pre-service teachers. Australian Journal of Teacher Education, 35, 104-120.

Boyes, E., \& Stanisstreet, M. (1993). The greenhouse effect children's perceptions of causes, consequences and cures. International Journal Science Education, 15, 531-552.

Boyes, E., \& Stanisstreet, M. (1997). Children's models of understanding of two major global environmental issues (ozone layer and greenhouse effect). Research in Science and Technological Education, 15(1), 19-28.

Boyes, E., \& Stanisstreet, M. (2001). Global warming: What do high school students know 10 years on? World Resource Review, 13(2), 221-238.

Boyes, E., Skamp, K., \& Stanisstreet, M. (2009). Australian secondary studentsary studentsary obal warming: Beliefs about actions, and willingness to act. Research in Science Education, 39(5), 661-680.

Boyes, E., Stanisstreet, M., \& Yongling, Z. (2008). Combating global warming: The ideas of high school students in the growing economy of South East China. International Journal of Environmental Studies, 65(2), 233-245.

Breslyn, W., McGinnis, J.R., McDonald, C., \& Hestness, E. (2016). Developing a learning progression for sea level rise, a major impact of climate change. Journal of Research in Science Teaching, 53(10), 1471-1499.

Brickhouse, N., McGinnis, J.R., Shea, N., Drewes, A., Hestness, H., \& Breslyn, W. (2017). Core idea ESS3: Earth and human activity. In: Ravit, R.G., Krajick, J., \& Rivet, A., (Eds.), Disciplinary Core Ideas: Reshaping Teaching and Learning. Arlington, VA: NSTA. pp. 223-240.

Cohen, J. (1988). Statistical Power Analysis for the Behavioral Sciences. Hillsdale, NJ: Erlbaum.

Cook, J., Oreskes, N., Doran, P.T., Anderegg, W.R., Verheggen, B.,
Maibach, E.W., \& Nuccitelli, D. (2016). Consensus on consensus: A synthesis of consensus estimates on human-caused global warming. Environmental Research Letters, 11(4), 048002.

Cronbach, L.J. (1951). Coefficient alpha and the internal structure of tests. Psychometrika, 16, 297-334.

Daniel, B., Stanisstreet, M., \& Boyes, E. (2004). How can we best reduce global warming? Students' ideas and misconception. International Journal of Environmental Studies, 61(2), 211-222.

Drewes, A., Breslyn, W., McGinnis, R., Mouza, C., Hestness, E., \& Henderson, J. (2017). Designing and Validating a Climate Change Knowledge Instrument. San Antonio, TX: Proposal Presented at American Educational Research Association Annual Conference.

Duncan, R., \& Hmelo-Silver, C. (2009). Learning progressions: Aligning curriculum, instruction and assessment. Journal of Research in Science Teaching, 46(6), 606-609.

Dunlap, W.P., Cortina, J.M., Vaslow, J.B., \& Burke, M.J. (1996). Metaanalysis of experiments with matched groups or repeated measures designs. Psychological Methods, 1, 170-177.

Duschl, R.A., Schweingruber, H.A., \& Shouse, A.W. (Eds.). (2007). Taking Science to School: Learning and Teaching Science in Grades $\mathrm{K}-8$. Washington, DC: National Academies Press.

Ebel, R.L. (1954). Procedures for the analysis of classroom tests. Educational and Psychological Measurement, 14, 352-364.

Evagorou, M., Guven, D., \& Mugaloglu, E. (2014). Preparing elementary and secondary pre-service teachers for everyday science. Science Education International, 25(1), 68-78.

Feierabend, T., \& Eilks, I. (2010). Raising studentssing studentsdentsstudentsg studentsparing elementary and secondary pre-service teachers for everyday science. ecly reflect the views of the NSF. develops. Furthees in the framework of climate change. Science Education International, 21(3), 176-196.

Furtak, E.M. (2012). Linking a learning progression for natural selection to teachers' enactment of formative assessment. Journal of Research in Science Teaching, 49(9), 1181-1210.

Golden, B. (2011). Middle School Students' Conceptual Change in Global Climate Change: Using Argumentation to Foster Knowledge Construction. Tallahassee, FL: Unpublished Doctoral Dissertation, Florida State University.

Gotwals, A.W., \& Songer, N.B. (2010). Reasoning up and down a food chain: Using an assessment framework to investigate students' middle knowledge. Science Education, 94(2), 259-281.

Gowda, M.R., Fox, J.C., \& Magelky, R.D. (1997). Students' understanding of climate change: Insights for scientists and educators. Bulletin of the American Meteorological Society, 78(10), 2232-2240.

Hansen, P.J.K. (2010). Knowledge about the greenhouse effect and the effects of the ozone layer among Norwegian pupils finishing compulsory education in 1989, 1993, and 2005-what now? International Journal of Science Education, 32(3), 397-419.

Hestness, E., McDonald, R.C., Breslyn, W., McGinnis, J.R., \& Mouza, C. (2014). Science teacher professional development in climate change education informed by the Next Generation Science Standards. Journal of Geoscience Education, 62(3), 319-329.

Hestness, E., McGinnis, J.R., \& Breslyn, W. (2016). Examining the relationship between middle school students' sociocultural participation and their ideas about climate change. Environmental Education Research, 1-13. DOI: 10.1080/13504622.2016.1266303.

Hestness, E., McGinnis, J.R., Breslyn, W., McDonald, C., \& Mouza, C. (2017). Examining science educators' perspectives on learning progressions in a climate change education professional development program. Journal of Science Teacher Education, 28(3), 250-274.

Hestness, E., McGinnis, J.R., Riedinger, K., \& Marbach-Ad, G. (2011). A study of teacher candidates' experiences investigating global climate change education within an elementary science methods course. Journal of Science Teacher Education, 22, 351-369.

IPCC. (2014). Climate Change 2014: Synthesis Report. Contribution of Working Groups to the Fifth Assessment Report of the Intergovernmental Panel on Climate Change. Available from: https://www.ipcc.ch/report/ ar5/syr. [Last accessed on 2017 Aug 24].

Kaplan, R.M. \& Saccuzzo, D.P. (1997). Psychological Testing: Principles, Applications, and Issues. $4^{\text {th }}$ ed. Pacific Grove, CA: Brooks/Cole. 
Kilinc, A., Stanisstreet, M., \& Boyes, E. (2008). Turkish students' ideas about global warming. International Journal of Environmental and Science Education, 3(2), 89-98.

Kirk, K.B., Gold, A.U., Ledley, T.S., Sullivan, S.B., Manduca, C.A., Mogk, D.W., \& Wiese, K. (2014). Undergraduate climate education: Motivations, strategies, successes, and support. Journal of Geoscience Education, 62, 538-549.

Klosterman, M., \& Sadler, T. (2010). Multi-level assessment of scientific content knowledge gains associated with socioscientific issuesbased instruction. International Journal of Science Education, 32(8), 1017-1043.

Koulaidis, V., \& Christidou, V. (1999). Models of students' thinking concerning the greenhouse effect and teaching implications. Science Education, 83(5), 559-576.

Lee, O., Lester, B.T., Ma, L., Lambert, J., \& Jean-Baptiste, M. (2007). Conceptions of the greenhouse effect and global warming among elementary students from diverse languages and cultures. Journal of Geoscience Education, 55(2), 117-125.

Lehrer, R., \& Schauble, L. (2009). Images of learning, images of progress. Journal of Research in Science Teaching, 46(6), 731-735.

Liarakou, G., Athanasiadis, I., \& Gavrilakis, C. (2011). What Greek secondary school students believe about climate change? International Journal of Environmental and Science Education, 6(1), 79-98.

Liu, S., Roehrig, G.H., Bhattacharya, D., \& Varma, K. (2015). In-service teachers' attitudes, knowledge and classroom teaching of global climate change. Science Educator, 24(1), 1-11.

McBeth, B., Hungerford, H., Marcinkowski, T., Volk, T., Cifranick, K., Howell, J., \& Meyers, R. (2011). National Environmental Literacy Assessment, Phase Two: Measuring the Effectiveness of North American Environmental Education Programs with Respect to the Parameters of Environmental Literacy, Final Report. Available from: https://www. seek.state.mn.us/resource/national-environmental-literacy-assessmentphase-two. [Last accessed on 2017 Aug 24].

McGinnis, J.R., Hestness, E., \& Riedinger, K. (2011). Changing science teacher education in a changing global climate: Telling a new story. In: Ling, J., \& Oxford, R., (Eds.), Transformative Eco-Education for Human Survival: Environmental Education in a New Era. Charlotte, NC: Information Age Publishing. pp. 117-133.

McGinnis, J.R., McDonald, C., Breslyn, W. \& Hestness, E. (2017). Supporting the inclusion of climate change in U.S. Science education curricula by use of learning progressions. In: Shephardson, D., Roychoudury, A., \& Hirsch, A., (Eds.), Teaching and Learning about Climate Change: A Framework for Educators. New York, NY: Routledge. pp. 135-151.

McGinnis, J.R., McDonald, C., Hestness, E., \& Breslyn, W. (2016). An investigation of science educators' views of roles and responsibilities for climate change education. Science Education International, 27, 179-192

Melillo, J.M., Richmond, T.T., \& Yohe, G. (2014). Climate Change Impacts in the United States, Third National Climate Assessment. Available from: http://www.s3.amazonaws.com/nca2014/low/NCA3_Climate_Change_ Impacts_in the_United\%20States_LowRes.pdf. [Last accessed on 2017 Aug 24].

Mohan, L., Chen, J., \& Anderson, C.W. (2009). Developing a multi-year learning progression for carbon cycling in socio-ecological systems. Journal of Research in Science Teaching, 46(6), 675-698.

Monroe, M.C., Oxarart, A., \& Plate, R.R. (2013). A role for environmental education in climate change for secondary science educators. Applied Environmental Education and Communication, 12(1), 4-18.

NGSS Lead States. (2013). Next Generation Science Standards: For States, by States. Washington, DC: The National Academy Press.

Niebert, K., \& Gropengieber, H. (2014). Understanding the greenhouse effect by embodiment-analysing and using students' and scientists' conceptual resources. International Journal of Science Education, 36(2), 277-303.

Plummer, J.D., \& Krajcik, J. (2010). Building a learning progression for celestial motion: Elementary levels from an earth-based perspective. Journal of Research in Science Teaching, 47(7), 768-787.

Plutzer, E., McCaffrey, M., Hannah, A.L., Rosenau, J., Berbeco, M., \& Reid, A.H. (2016). Climate confusion among US teachers. Science, 351(6274), 664-665.

Punter, P., Ochando-Pardo, M., \& Garcia, J. (2011). Spanish secondary school students' notions on the causes and consequences of climate change. International Journal of Science Education, 33(3), 447-464.

Ratinen, I., Viiri, J., \& Lehesvuori, S. (2013). Primary school student teachers01understanding of climate change: Comparing the results given by concept maps and communication analysis. Research in Science Education, 43(5), 1801-1823.

Rebich, S., \& Gautier, C. (2005). Concept mapping to reveal prior knowledge and conceptual change in a mock summit course on global climate change. Journal of Geoscience Education, 53(4), 355-365.

Reinfried, S., Aeschbacher, U., \& Rottermann, B. (2012). Improving students' conceptual understanding of the greenhouse effect using theory-based learning materials that promote deep learning. International Research in Geographical and Environmental Education, 21(2), 155-178.

Sharma, A. (2012). Global climate change: What has science education got to do with it? Science and Education, 21(1), 33-53.

Shea, N., \& Duncan, R.G. (2013). From theory to data: The process of refining a learning progression. Journal of the Learning Sciences, 22(1), 7-32.

Shea, N., Mouza, C., \& Drewes, A. (2016). Climate change professional development: Design, implementation, and initial outcomes one teacher learning, practice, and student beliefs. Journal of Science Teacher Education, 27, 235-258.

Shepardson, D.P., Niyogi, D., Choi, S., \& Charusombat, U. (2009). Seventh grade students' conceptions of global warming and climate change. Environmental Education Research, 15(5), 549-570.

Songer, N., Kelcey, B., \& Gotwals, A. (2009). How and when does complex reasoning occur? Empirically driven development of a learning progression focused on complex reasoning about biodiversity. Journal of Research in Science Teaching, 46(6), 610-631.

Sullivan, S.B., Ledley, T.S., Lynds, S.E., \& Gold, A.U. (2014). Navigating climate science in the classroom: Teacher preparation, perceptions and practices. Journal of Geoscience Education, 62(4), 550-559.

Thorndike, R.L. (1982). Applied Psychometrics. Boston: Houghton Mifflin.

Wise, S.B. (2010). Climate change in the classroom: Patterns, motivations, and barriers to instruction among Colorado science teachers. Journal of Geoscience Education, 58(5), 297-309. 